\title{
JUVENILE PARESIS IN ONE TWIN
}

\author{
BY \\ REDVERS IRONSIDE \\ From the Neurological Department, West London Hospital
}

(ReCEIVED 24TH July, 1940)

\begin{abstract}
Introduction
IT is now widely accepted that congenital syphilis is an infection that is acquired in utero from the mother, usually in the later months of pregnancy. It is not perhaps so widely recognized that in the case of twin pregnancies it is not unusual for the twins to suffer the luetic infection unequally. One twin may be born healthy, the other diseased; or if both are diseased the symptoms may appear at differing periods after birth and vary in severity in the two infants. This may be true for monozygous as well as dizygous twins. A considerable number of cases illustrating these facts have now been published, and the reader may be referred to the papers with bibliographies of Haslund (1924) and Bergel and Zimmermann (1932).

" The literature of syphilis," said Jonathan Hutchinson, " is encumbered with ill-founded opinions and untrustworthy facts." It is unfortunate that in many of the cases reported in the era of the Wassermann reaction, the " healthy" twin has been kept under observation for a few weeks or months only. The syphilitic twin has usually died and a post-mortem has established the diagnosis. The zealous author, fearful lest his enthusiasm should wane, records the case without observation of the apparently unaffected twin over a sufficiently lengthy period of time to prove the freedom from latent infection. In rare cases the twins survive infancy, and symptoms of delayed congenital syphilis appear in later childhood. Here again it is not infrequent to find total escape or mild infection of one twin while the other shows the disease in severe degree.

The following exposition of a case of juvenile paresis in one twin, the other twin completely escaping infection, provides further proof of the vagaries of prenatal infection. The twins have been under observation at the West London Hospital for the past seven years. Repeated clinical examinations and serological tests of blood and cerebrospinal fluid have been made over this period, not only on the twins but on the other members of the family.
\end{abstract}

\section{Case Records}

George and Thomas R., aged 17 years, are twin brothers of a second pregnancy. There is one older brother, James R., aged 27 years. The mother has been pregnant 
on two occasions only, and there have been no miscarriages. Her health during pregnancy was excellent and the twin labour was normal. George, the smaller twin, who weighed $5 \frac{1}{2} \mathrm{lb}$. at birth, was born one hour before Thomas, who weighed $6 \frac{3}{4} \mathrm{lb}$. at birth. Both twins were breast fed for 9 months.

The Affected Twin.-George R. at birth was smaller than his twin brother and was always more backward physically and mentally. During infancy he suffered from chicken-pox and measles, but never had a sore, and never suffered from rash, sore mouth, eye trouble, or convulsions. At the age of 5 years he went to school, but could not learn as well as his twin. When 10 years of age his physical condition began to deteriorate and he was sent for some months to Harefield Sanatorium under suspicion of tuberculosis. The diagnosis of tuberculosis was never confirmed, but it was found at the Sanatorium that his blood Wassermann was positive. Between the ages of 11 and 15 years he was treated as an out-patient at the West London Hospital Clinic, receiving in all $10 \mathrm{gm}$. of N.A.B. and 60 c.c. of bismuth compounds. At the age of 15 years the blood Wassermann was strongly positive and the blood Kahn was weakly positive. The cerebrospinal fluid was not examined. He then ceased to attend.

At the age of 17 years he was brought by his mother to the West London Hospital Neurological Department. She stated that he had left school at the age of 14 years 9 months, but had never been able to go to work. Although he had passed through a Board School education and had learned to spell, write, and perform simple calculations, and could at that time be trusted with money, he was regarded by his mother as a backward child. His disposition had been affectionate and quiet. .From the age of 15 years mental deterioration had set in, thought by the parents to be due to a slight head injury. He became more childish in every way. If told to wash he would put his hands in the water but not rinse or soap them, he lost the ability to dress himself, and would not clean his shoes. Bursts of irritability were frequent, when he would pinch or kick his parents or throw knives, forks, or plates at those with whom he was annoyed. He became very sensitive to noise and would display temper if something was said to him which he could not understand. His memory failed, so that he could no longer be trusted to perform errands or be trusted with money. He retained, however, the names of the football teams which he continued to mark on his weekly coupon. If left alone in the house he would mischievously switch on lights and wireless, open the windows, and carelessly let the fire go out. In attempting to relight the fire he would strew ashes and wood and paper on the carpet. He could no longer read, write, or calculate. His speech became stuttering, rapid, and indistinct. No fits or convulsions had occurred.

On examination at the age of 17 years the patient weighed $87 \frac{1}{2} \mathrm{lb}$. and his height was $62 \frac{1}{2}$ inches. Stigmata of congenital syphilis were absent. Specifically he showed no Hutchinson's teeth, no interstitial keratitis or chorio-retinitis, no rhagades, deafness, nor sabre deformities of the tibiæ. He was of poor nutrition and physique, and exceedingly tremulous, ataxic, and dysarthric. His speech was indistinct, precipitate, and toneless. He stuttered and repeated the end syllables of words. His stutter was accompanied by overaction and tremors of the facial muscles and lips, and a constant tic-like protrusion of the tongue. Vocabulary was limited and he had difficulty in forming sentences. He could recognize and name objects and well-known persons portrayed in a picture paper. The optic discs, pupils, and cranial nerves were all normal apart from coarse tremors of the lips and tongue. The upper limb movements were clumsy and inco-ordinate, and the gait was wide-based, reeling, and ataxic so that he needed support to walk. This ataxia was of the cerebellar type. The biceps, triceps, and supinator jerks were all brisk and equal. Both plantar responses were extensor ; the abdominal reflexes were present upper and lower. Sensory testing in detail was not possible owing to his mental state, but vibration and sense of position appeared normal, and there was no defect of pain on pressure of the Achilles tendons. The heart was normal in size and the sounds clear. The resting pulse rate was 70 per minute, the blood pressure $=120 / 65$. No disease could be detected in the chest or 
abdomen. The urine was acid and had a sp. gr. 1,020 and contained no albumen or sugar.

He was removed at the request of his mother to Springfield Mental Hospital. There he lay restlessly in bed, playing untidily with a child's pack of cards. Malarial treatment had been given, with little effect on the mental condition.

The cerebrospinal fluid analysis on admission showed : Cells $=25$ per cu. $\mathrm{mm}$. ( 50 per cent. small mononuclear ; 40 per cent. medium mononuclear ; 10 per cent. large mononuclear) ; globulin $=$ Pandy +++ , Nonne Apelt +++ ; albumen $=0 \cdot 1$ per cent. ; chlorides $=730$ mgs. per cent. ; Lange curve $=5.5 .5 .5 .5 .5 .5 .4 .3 .2 ; K a h n=$ strong positive ; W.R. $=$ positive ++ ; blood $\mathrm{Kahn}=$ positive 2.1 ; blood W.R. $=$ strong positive ++ .

The Healthy Twin.-Thomas R. was physically and mentally normal from birth. He went to school aged 5 years and left at the age of 14 years to work in a celluloid factory. The blood Wassermann reaction and Kahn tests were negative when he was aged 11, and between the ages of 11 and 14 years four similar tests at intervals gave negative results. He now works as a machine hand in a factory.

Examination at the age of 17 years showed that he was a mentally alert young man of good nutrition and physique. His weight was $134 \mathrm{lb}$. and his height $70 \frac{1}{4}$ inches. Stigmata of congenital syphilis were absent. His speech and articulation were normal and no tremors of the tongue, face, or limbs were observed. The optic discs, pupils, and cranial nerves were normal. The limbs were strong and steady at all joints, and there was no ataxia on walking. Detailed sensory testing revealed no abnormality. The tendon reflexes were brisk and equal, the plantar responses flexor, and the abdominals brisk, upper and lower. The heart was normal in size and the sounds clear. The resting pulse rate was 65 per minute and the blood pressure measured $130 / 65$. There was no disease in the chest or abdomen and the urine was normal.

The cerebrospinal fluid analysis at the age of 17 years showed : Cells $=0$ per cu. $\mathrm{mm}$. ; total protein $=0.025$ per cent. ; globulin $=$ Pandy-a faint trace, Nonne Apelt-a faint trace ; Lange curve =1.1.0.0.0.0.0.0.0.0. ; Kahn $=$ negative ; W.R. $=$ negative. Blood Wassermann and Kahn tests (the fifth time of testing) were completely negative.

The Sib.-The elder brother, James R., aged 27 years, is a builder. He showed no clinical abnormality on detailed testing, and the blood Wassermann reaction was negative. He is married and has two healthy children.

The Father.-The father, William R., aged 46 years, is a fitter. He has always been healthy except for a recent duodenal ulcer, and he denies venereal disease. Detailed neurological and general physical examinations reveal no abnormality. The blood Wassermann and Kahn tests were negative at the age of 46 years.

The Mother.-The mother, Mrs. Eleanor R., is aged 46 years. The twins were born in 1922, when she was 29 years old, four years after her husband's return from active service in France and Italy, 1914 to 1918. At the age of 38 years she attended the West London Hospital for what at first appeared to be a suppurating pre-patellar bursa of the left knee which was soon found to be a gumma. The blood W.R. was then ++++ and the Kahn test positive 4.4.3. After treatment for four years the blood W.R. was ++ and the Kahn 2.2.

On examination at the age of 46 years she showed no clinical abnormality on detailed testing other than a healed scar on the front of the left knee. The blood Wassermann was still ++ and the Kahn test positive.

The cerebrospinal fluid analysis showed : Cells $=2$ per cu. $\mathrm{mm}$. ; total protein $=0.01$ per cent. ; Lange curve $=0.0 .0 .0 .0 .0 .0 .0 .0$. W.R. $=$ completely negative.

\section{Data Regarding the Twinning}

There is a marked family history of twinning on the mother's side of the family.

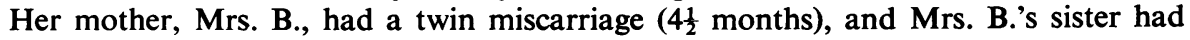


twin boys. Mrs. R.'s maternal grandmother had twins, a boy and a girl. The wife of Mrs. R.'s brother, Alfred, has twin sons.

Thomas and George R. are dizygous twins. I am indebted to Dr. R. Race, of the Galton Laboratory Serum Unit, University College, London, for proving this conclusively for me. In Dr. Race's investigations the $\mathrm{M} \mathrm{N}$ blood-group system settled the zygosity. Thomas was $\mathrm{O} \mathrm{N}$ and George $\mathrm{O} \mathrm{M} \mathrm{N}$ (Fig. 1).

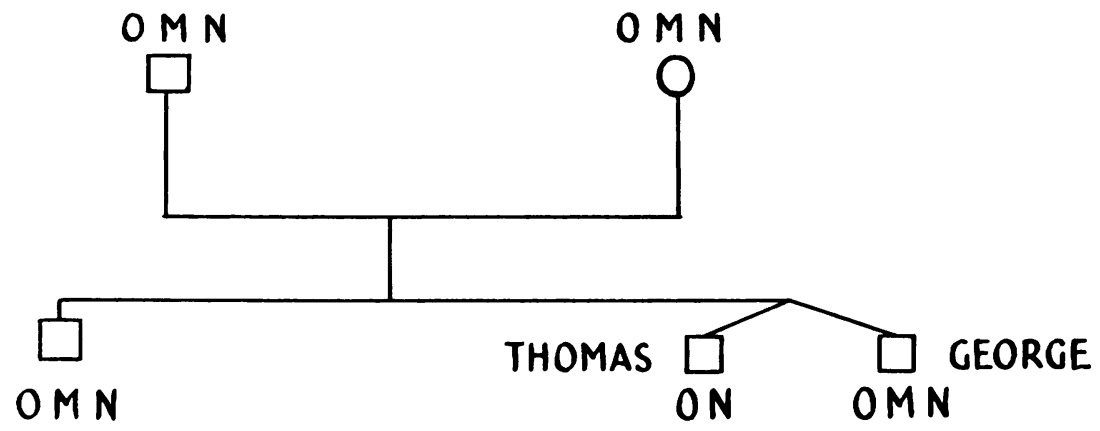

Fig. 1.

There is no connection between the A B O system and the M N. They are inherited on different pairs of chromosomes.

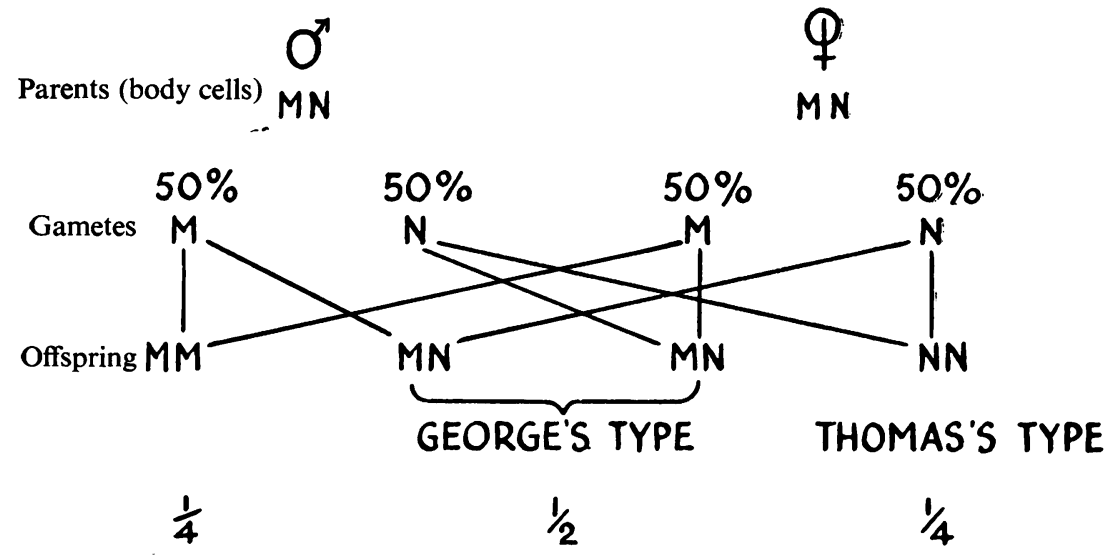

Fig. 2.

George has had an $\mathrm{M}$ from one parent and an $\mathrm{N}$ from another, while Thomas has had an $\mathbf{N}$ from both (N N or $\mathbf{M} \mathbf{M}$ are called $\mathbf{N}$ or $\mathbf{M}$ ) (Fig. 2).

Anthropometric observations regarding iris colour and pigment pattern, hair colour and whorl, fingerprints, etc., corroborated that the twins were dissimilar.

\section{Discussion}

Even in the absence of stigmata of congenital syphilis it seems unlikely that the infection of the paretic twin was a post-natally acquired one. According to Menninger congenital syphilitic stigmata are completely absent in 25 per cent. of juvenile paretics. No history of primary sore or rash in George's childhood could be ascertained. As in most cases of congenital syphilis the mother showed signs of the infection but not the father. 
Mental retardation had been present since infancy. Physical deterioration began at the age of 10 years, but it was not until five years later that mental deterioration and regression commenced. It is likely that the early mental retardation was due to congenital syphilis. Approximately 40 per cent. of all cases of juvenile paresis are feeble-minded from birth, although the disease classically begins in a previously normal child in later childhood. Not all cases of feeble-mindedness due to syphilis turn out to be cases of juvenile paresis, nor will the finding of a paretic gold curve alone in the spinal fluid justify the diagnosis of paresis. The clinical examination must demonstrate the neurological signs of the disease and the serological picture in the spinal fluid must be complete in respect of pleocytosis, increase in globulin, and positive Wassermann reaction. In the feeble-minded group of congenital paretics the disease is insidious in onset, running a relatively long course as compared with the acquired form of the disease.

\section{Other Cases in the Literature}

Juvenile paresis is itself so rare that its occurrence in a twin must be very rare indeed. A search of the literature as far back as 1906 (the year of the discovery of the Wassermann reaction) has revealed one other case of juvenile paresis in a twin and one case of juvenile tabo-paresis in a twin. Cases of cerebral syphilis, such as Dennie described, have been excluded.

Wile and Welton (1938) described dizygous twin brothers, aged 18 years, one of whom was healthy, the other suffering from juvenile paresis. The twins were a seventh pregnancy and were dissimilar, as evidenced by different iris colour and pigment pattern, different hair colour, and no point of similarity in comparison of foot patterns or fingerprints. Detailed anthropometric observations tabulated in their paper combined with the above evidence to leave little doubt as to the dizygous nature of the twinning. The healthy, non-syphilitic, twin was born 45 minutes before his brother, to whom he was always mentally and physically superior. During the period of one year in which he was kept under observation he showed no clinical evidence of neurosyphilis; five blood Wassermann reactions were negative ; and one cerebrospinal fluid analysis was completely negative. The paretic twin was mentally dull and backward from infancy. He had frontal and parietal bosses, pegshaped upper central incisor teeth, one notched, and anterior thickening of both tibix. Central and disseminated chorioretinitis was present in both fundi. Little information is given as to progressive mental deterioration except that he was slow in answering and had difficulty in reading. His pupils were unequal and fixed, he was dysarthric with tremor of the lips and tongue, and both plantar responses were extensor. The blood Wassermann and Kahn tests were repeatedly positive and the cerebrospinal fluid analysis was typical of paresis, viz. : Cells $=29$ lymphocytes per cu. $\mathrm{mm}$.; globulin = positive ; total protein $=0.43$ per cent.; Kahn $=++$; Lange curve +5.5 .5 .4 .3 .2 .1 .0 .0 .0 .0 .

Blood Wassermann reactions on five surviving sibs were uniformly negative. The father was normal on careful physical examination, and his blood Wasser- 
mann was negative on the two occasions on which it was taken. The mother, however, had a strongly positive blood Wassermann, but refused any further examination.

McKendree (1937) described twin sisters, aged 13 years, possibly monozygous, one of whom was healthy, the other suffering from tabo-paresis. This case is of extreme clinical importance in view of the possibility that the twins are monozygous. The twins had similar facial features, like colouring of hair and eyes, and the father said he had seen only one afterbirth. No details of clinical findings in the case of the healthy non-syphilitic twin were given, but the cerebrospinal fluid analysis was negative with a negative Lange curve, and the blood Wassermann was negative, although whether on more than one occasion is not recorded. The paretic twin was always dull and backward and physically smaller than her healthy sister. Semilunar notches were present in both upper central incisor teeth. She was a happy imbecile, dysphasic and dysarthric. There was a right external strabismus. The pupils reacted sluggishly to light and the right was larger than the left. The right ankle jerk could not be elicited. The blood Wassermann reaction was positive and the cerebrospinal fluid analysis showed: Cells $=2$ per cu. $\mathrm{mm}$. ; globulin $=\mathrm{a}$ trace ; W.R. $=++$; Lange curve $=5 \cdot 5 \cdot 5 \cdot 4 \cdot 3.2 .1 .0 .0 .0$. Three surviving sibs of the twins had completely negative blood Wassermann reactions. Both parents were known to be syphilitic and the mother had had three miscarriages.

No case of juvenile tabes appears to have been recorded since 1906. Whitmore (1924) described as tabetic mentally defective twin sisters aged 10 years. One had optic atrophy and interstitial keratitis, the other had an Argyll Robertson pupil. In both cases the reflex functions were normal. Both had a pleocytosis in the cerebrospinal fluid and a positive blood Wassermann reaction. The cerebrospinal fluid Wassermann was negative in the twin with the optic atrophy and positive in the other. Whitmore's twins are probably cases of cerebral syphilis and not juvenile tabes as he asserted: a demonstration of tabetic mask anæsthesia in mentally defective children of 10 years old is unconvincing.

These interesting cases of delayed congenital neurosyphilis prove that in twins total escape or mild infection of one twin may occur while the other suffers the full onslaught of the disease. The phenomenon of the escape of the healthy twin is of great speculative interest. In dizygous cases both twins and both placentas must be equally exposed to the maternal spirochætæmia; but it seems that syphilitic disease may affect the placentas unequally or at different periods of uterine life. Why a syphilitic focus should appear in one placenta and not in the other is obscure. In monozygous cases where one placenta has been shared by both twins the apparent escape from infection of one fœtus is even more difficult of explanation.

It is curious and interesting to note the development of paresis in the acquired form in both twins at approximately the same age, as described by Clouston and Savage (1888). They described twin brothers, apparently dizygous, aged 37 years, both commercial travellers. Primary infection appears to have taken place about the same time and the brothers developed paresis at 
approximately the same age. The one was admitted to the Royal Edinburgh Asylum under Sir Thomas Clouston and the other to the Royal Bethlem Hospital under Dr. George Savage. Although these cases occurred before the era of serological tests, there can be little doubt from the masterly clinical descriptions given that they were really cases of paresis. In the Bethlem case there was a post-mortem with characteristic findings.

I have to thank Mr. Keith Duff, of the West London Hospital, for information regarding the earlier history of the R. family. To Dr. John H. Ewen, the Medical Superintendent of Springfield Mental Hospital, I am indebted for the cerebrospinal fluid analysis of the affected twin, and to Dr. R. Race, of the Galton Laboratory Serum Unit, for data regarding the blood-grouping of the twins.

\section{REFERENCES}

Bergel, A., and Zimmermann, O. (1932). Med. Klinik., 28, 1668.

Clouston, T. S., and Savage, G. H. (1888). J. ment. Sci., 34, 65.

Dennie, C. C. (1924). Med. Clin. N. Amer., 7, 1219.

Friedenreich, V. (1938). Blood Groups and Genetics (Galton Lectures). Ann. Eugen. 8, 152.

Haslund, O. (1924). Ann. Derm. Syph., Paris, 5, 321.

McKendree, O. J. (1937). N.Y. St. J. Med., 37, 659-662.

Menninger, W. C. (1936). Juvenile Paresis. Williams and Wilkins Co., Baltimore.

Whitmore, F. (1924). Minnesota Med., 7, 430.

Wile, U. J., and Welton, D. G. (1938). Amer. J. Syph., 22, 544-554. 